\title{
ADJUDiCACión, VALORES FUNDAMENTALES Y DiÁLOGO
}

\author{
Matías GuilofF ${ }^{*}$
}

RESUMEN: El presente artículo asume como premisa y a la vez intenta explicar la principal manera en que se resuelven los desacuerdos en Chile, a través de la judicialización de la política. Sobre esta base expone las múltiples dificultades que esa manera de resolver los desacuerdos conlleva, para lo cual parte por abordar, desde la perspectiva teórica constitucional comparada, algunas de estas, especificamente las que dicen relación con la idea de que las cortes disciplinan la política a través de la imposición de valores fundamentales y luego se adentra en un análisis de la práctica jurisprudencial en lo que dice relación con dos de las materias que boy en día originan muchos de estos desacuerdos, las demandas por reconocimiento y redistribución.

Palabras Clave: Judicialización de la política - Desacuerdos Adjudicación - Valores fundamentales - Ponderación de derechos fundamentales.

\section{Adjudication, FUndamental values and dialogue}

ABSTRACT: This paper assumes as a premise and tries to explain Chile's main manner of solving its disagreements, through the judicialization of politics. On said grounds it exposes the various difficulties that this form of solving disagreements entails, for the purposes of which it starts by addressing from a compared constitutional theory perspective some of them, specifically those dealing with the idea that courts discipline politics through the imposition of fundamental values. Next, it scrutinizes judicial decisions in Chile dealing with two of the issues that cause much of these disagreements, demands for recognition and redistribution.

Licenciado en Ciencias Jurídicas y Sociales de la Universidad Diego Portales. LL.M. Columbia University (EE.UU.). Profesor de Derecho en la Universidad Diego Portales. Correo electrónico: mguiloff@gmail.com

Este artículo fue presentado en la "Primera Jornada de Teoría e Interpretación Jurídica", los días 18 y 19 de octubre del año 2007, en la Escuela de Derecho de la UNIVERSidad CatóLICA DEL NorTE. Agradezco a Alejandro Robledo y Felipe Quezada la posibilidad de participar en esa actividad. Agradezco además a Jorge Contesse por sus comentarios, a Domingo Lovera por sus sugerencias y a Nicolás Espejo por su estímulo.

Fecha de recepción: 03 de enero de 2008.

Fecha de aceptación: 30 de mayo de 2008. 
KEY WORDs: Judicialization of politics - Disagreements Adjudication - Fundamental values - Fundamental rights balancing.

SUMARIO: I. ¿Por qué ante los desacuerdos que nos dividen (lo primero que se nos pasa por la cabeza es) ir a tribunales? 1. La explicación cultural. 2. La explicación institucional. 3. Algunas consecuencias de esta manera de resolver los desacuerdos. II. Nuestros tribunales y nuestros desacuerdos. 1. Adjudicación de demandas por reconocimiento. 2. Adjudicación de demandas por redistribución. Conclusiones.

Ninguna línea clara divide a la filosofía del derecho de la adjudicación o de cualquier otro aspecto de la práctica legal. Los filósofos del derecho discuten sobre la parte general, el fundamento interpretativo que cualquier argumento legal tiene que tener.

Cualquier argumento legal práctico, sin importar cuán detallado o limitado sea, asume el tipo de fundamentación abstracta que la filosofía del derecho of rece y cuando diversas fundamentaciones compiten, un argumento legal acepta una y rechaza la otra.

Asi cualquier opinión judicial es en sí misma una pieza de filosofía del derecho, aun cuando esa filosofía se encuentre oculta y el argumento visible se encuentre dominado por citas y bechos. La filosofía del derecho es la parte general de la adjudicación, prólogo silencioso para toda decisión judicial.

RONALD DWORKIN ${ }^{\mathrm{I}}$

Dos de los dilemas más difíciles que deben enfrentar las sociedades modernas, sino los más difíciles, dicen relación con cómo hacer frente a las demandas de reconocimiento y distribución ${ }^{2}$. En tanto sociedad moderna, la chilena no se encuentra ajena a esta tendencia y es así como en los últimos años temas tales como leyes de cuotas y la creación de un diálogo social han puesto de manifiesto en la agenda pública estas demandas ${ }^{3}$. Con todo, el fenómeno es bastante reciente y ante la inercia que como sociedad

I Dworkin, Ronald (1987) Law's Empire. Cambridge (Massachusetts): Belknap Press, p 90. La traducción es mía,

2 Espejo, Nicolás (2007) "Reconocimiento y redistribución: el rol de una teoría crítica de la democracia". En Arango, Rodolfo (editor académico). Filosofía de la democracia. Fundamentos conceptuales. Bogotá (Colombia): Siglo del Hombre Editores, pp. 237-267.

Además, Contesse, Jorge "Constitucionalismo interamericano: posibilidades no dogmáticas para el progreso". En Gargarella, R., Rodríguez, C. \& Uprimny, R., Constitucionalismo Igualitario para América Latina (2008, en prensa).

3 "Bachelet defendió su Ley de Cuotas: No es feminismo", Radio Cooperativa, disponible en http://www.cooperativa.cl/p4_noticias/antialone.html?page=http://www.cooperativa.cl/p4_ noticias/site/artic/20060616/pags/20060616105119.html [fecha de visita, 19 de diciembre de 2007]

"Cardenal Errázuriz llama a dar forma a un gran pacto social", El Mercurio, 18 de septiembre, disponible en http://www.emol.com/noticias/nacional/detalle/detallenoticias. asp? idnoticia $=275865$ [fecha de visita, 19 de diciembre de 2007] 
hemos tenido para colocar estos temas dentro del debate público, aprovechando el lenguaje vago y teñido de valores que caracteriza a las cláusulas constitucionales, han sido litigantes particulares quienes han planteado este tipo de demandas (en el más jurídico de los sentidos que esta palabra puede aceptar) ante los tribunales de justicia. Ante la ineludible (o en términos de nuestra constitución, inexcusable) responsabilidad de resolver la situación planteada por estos casos, nuestros jueces de manera más o menos solapada han debido teorizar sobre nuestros valores fundamentales y sus particulares exigencias en lo que a reconocimiento y redistribución se refiere.

Con todo, creo que la explicación de la presencia de estos temas dentro de los tribunales de justicia es bastante más compleja de la que acabo de esbozar. Hay cuestiones sociológicas, propias de nuestra cultura, a las que este fenómeno se puede atribuir. Dentro de ellas puedo destacar una que dice relación con una visión del rol de los jueces y otra con una (mala) imagen de la deliberación política. En lo que se refiere a la primera, es posible advertir una percepción ciudadana de la función jurisdiccional que concibe a los tribunales desde un punto de vista funcional como tribunales de justicia en un hiperatrofiado sentido. Por si lo que he señalado anteriormente de buenas a primeras puede resultar inentendible, lo que quiero decir es que más que tribunales a los que uno recurre para tratar de resolver una disputa o agravio particularizado, los nuestros son muchas veces concebidos como los entes idóneos para obtener respuestas frente a auténticas y amplias demandas de justicia. Respecto a la segunda, dado que hay tan mala percepción de la discusión política muchas veces se opta por dejarla afuera de algunos ámbitos, sea quitándole influencia sobre la resolución sustantiva de algunos asuntos (neutralización de la política ${ }^{4}$ ) o entregándole la determinación a los tribunales de justicia (judicialización de la política ${ }^{5}$.

Siendo esto así y frente a las dificilísimas preguntas que plantean estos temas como sociedad, hemos preferido que personas aisladas del proceso político u otras especialistas en estos temas, pero actuando en el contexto de organismos en donde no se da una representación del todo democrática, sean quienes nos iluminen con sus respuestas. Cada uno de nosotros (válidamente) podrá tener su punto de vista acerca de la bondad de esta forma de resolver estos problemas. Con todo, para los efectos de

Al respecto, véase en general Rallo Lombarte, Artemi (2002). "La Constitucionalidad de las Administraciones Independientes". Madrid (España): Editorial Tecnos, 343 pp., p. 54. Véase en general Couso, Javier (2004) "Consolidación democrática y Poder Judicial: los riesgos de la judicialización de la política". Revista de Ciencia Politica. $24 \mathrm{~N}^{\circ} 2$, pp. 29-48. Disponible en http://www.scielo.cl/scielo.php?pid=S0718090X2004000200002\&script=sci_arttext [fecha de visita 20 de diciembre de 2007]. 
este paper asumiré una postura pragmática y partiré de la base que organismos distintos al Congreso son muchas veces los que deben dar respuestas frente a estas complejas preguntas. Más aun, no obstante lo atractivo y fundamental que en mi parecer es preocuparse desde el punto de vista filosófico político de aquellos organismos públicos que deciden cuestiones fundamentales de la manera más aislada de la política posible ${ }^{6}$, para los limitados propósitos de este paper centraré mi atención sobre cómo deben los tribunales de justicia resolver estos asuntos.

Así las cosas, este paper procede de la siguiente manera: En su primera parte trataré de desarrollar con un mayor grado de complejidad que lo hecho hasta aquí, porque cuestiones tan difíciles como el reconocimiento y la distribución encuentran respuestas en foros diversos al proceso político, para cuyos efectos sugeriré que el entregar la solución de estos asuntos a organismos (más o menos) despolitizados forma parte de nuestra narrativa en tanto sociedad y, consecuentemente, con posterioridad me explayaré sobre la antedicha idea de judicialización de la política. Luego, constatando que la realidad indica que estas demandas llegan a tribunales, argumentaré en relación a qué es lo que estos deben hacer frente a estas demandas, señalando en primer lugar la extrema dificultad de resoluciones judiciales acertadas en estas materias, para luego analizar en tanto casos difíciles qué podemos esperar de nuestros jueces cuando los enfrentan. Finalmente, esbozaré lo importante que me parece que estas cuestiones permanezcan abiertas en el contexto de una sociedad democrática.

\section{I. ¿POR QUÉ ANTE LOS DESACUERDOS QUE NOS DIVIDEN (LO PRIMERO QUE SE NOS PASA POR LA CABEZA ES) IR A TRIBUNALES?}

\section{La explicación cultural}

Como antes señalé, de la primera cuestión que me quiero ocupar es de buscar una explicación relativa a por qué problemas tan complejos y frente a los cuales existe gran desacuerdo en una sociedad como las demandas por reconocimiento y redistribución, son resueltos fuera de la instancia en donde es posible hacerlo de la manera más abierta y representativa, como es el proceso político. Como una cuestión básica que permite explicar esta reacción quiero referirme brevemente a la idea de narrativa. Quizás la principal obra a la que uno puede echar mano para entender a qué es lo que uno alude cuando habla de narrativa es Law's

Desde esta perspectiva, el análisis de organismos autónomos en nuestra Constitución como el Banco Central y la Contraloría General de la República aparece como un emprendimiento más que pendiente para nuestra teoría constitucional. 
Empire de Ronald Dworkin. Según nuestro autor, entremedio de la afirmación de que el derecho es simplemente una descripción fáctica (que él atribuye al positivismo de Hart, en su versión previa a su post scríptum) y aquella que aconseja una mirada instrumental (atribuida al pragmatismo) se sitúa la concepción del derecho como integridad7. Esta, "insiste que las proposiciones legales son juicios interpretativos y por tanto combinan elementos retrospectivos y prospectivos; ellas interpretan la práctica legal contemporánea visualizándola como una narrativa política en desarrollo... Así el principio adjudicativo de la integridad instruye a los jueces a identificar, hasta donde sea posible, derechos y deberes legales sobre la asunción de que todos ellos fueron creados por un autor individual -la comunidad personificada- expresando una concepción coherente de justicia e imparcialidad" 8

Si bien Dworkin nos habla de integridad y específicamente sobre narrativa tomando como sujeto a los jueces ${ }^{9}$, creo que es interesante extrapolar su idea y considerar como sujeto a la comunidad toda. En este sentido Robert Cover señala que "Ningún conjunto de instituciones legales o prescripciones existe independientemente de las narrativas que la sitúan y que le dan significado" 10 Desde esta perspectiva, la evaluación de nuestras prácticas actuales de argumentación legal debe ser hecha tomando en consideración cómo nuestra comunidad ha obrado durante su historia, nuestro lenguaje y todas aquellas cosas que nos definen en tanto cultura. Bajo el prisma de este análisis, recurrir a los tribunales de justicia en búsqueda de justicia en un sentido mucho más amplio que el de la casuística clásica de resolución de discretas controversias del todo ajenas a la discusión de grandes y generalizados problemas de justicia, aparece como un rasgo sobresaliente del universo normativo de nuestra cultura o en términos coverianos de nuestro nomos. Me parece posible advertir (para los propósitos de este paper) dos maneras en las que golpeando las puertas de los tribunales podemos hacer frente a injusticias materiales que aparecen palmarias o frente a inercias en el proceso político que se traducen en falta de respuestas frente a problemas que en el contexto de nuestra sociedad requieren de (alguna) solución.

La primera de estas situaciones es posible advertirla en casos que dicen relación con limitaciones al derecho de propiedad. Dentro de este contexto, es a lo menos significativo constatar que en periodos tan disí-

\footnotetext{
Dworkin (1986) 225. La traducción es mía. DWORKIN (1986) 225. La traducción es mía.

Esta es una de las principales críticas que se erigen en contra de Law's Empire. Ver MichelMAN, Frank (1986). "Traces of Self- Government", Harvard Law Review. Vol. 100, p. 76: "Hércules, el juez místico de Dworkin, es un solitario. Es heroico en demasía". La traducción es mía.

10 Cover, Robert (1983), "Nomos and Narrative". Harvard Law Review. Vol. 97, pp. 4-5.
} 
miles como a fines del siglo XIX (específicamente en $1889^{11}$ ), principios del siglo XX (1908 $\left.{ }^{12}\right)$, finales del mismo siglo (1984'13) e incluso principios del actual $\left(2003^{14}\right)$ frente a la percepción de injusticia que se observa en una medida de la administración que afecta una propiedad para beneficiar al resto de la comunidad, estas cuestiones se ventilen ante los tribunales de justicia, los que no obstante la diversidad de constituciones y leyes imperantes, acogen estas demandas fundándose en la injusticia e inequitatividad que las propiedades de los recurrentes deban soportar un gravamen que, en definitiva, beneficiará a la comunidad toda ${ }^{15}$. Desde esta perspectiva, los litigantes acuden a los tribunales para que estos apliquen justicia. Por su parte, los tribunales ante esta injusticia alegada hacen eco de esta alegación y fundan su disposición del caso en la misma; en este sentido, quizás lo más gráfico es lo que señala nuestra Corte Suprema al resolver el caso Comunidad Galletué versus Fisco en 1984, "[L]a procedencia de la acción de cobro de perjuicios, tiene como sustento en este caso a la equidad y la justicia atendidos los hechos que asienta el fallo impugnado, en el supuesto de que no hay ley concreta que resuelva el conflicto suscitado." 16 .

11 Corte de Apelaciones de Valparaíso, 5 de junio de 1889. "Ábalos con Fisco". Gaceta de Tribunales, año 49 , sentencia $\mathrm{N}^{\circ} 5185$.

12 Corte Suprema, 8 de enero de 1930. "Lapostol con Fisco". Revista de Derecho y Jurisprudencia T. XXVII (1930), segunda parte, sección primera, pp 744-748.

13 Corte Suprema, 7 de agosto de 1984. "Comunidad Galletué con Fisco de Chile". Revista de Derecho y Jurisprudencia. T. LXXXI N ${ }^{\circ} 3$, segunda parte, sección quinta.

14 Corte de Apelaciones de Santiago, 21 de noviembre de 2003. Rol No 68281999. "Sociedad Agrícola Lolco Limitada con Fisco de Chile". Gaceta Juridica N ${ }^{\circ} 281$, pp. 122-129.

15 En contra de esta línea de argumentación podría esbozarse que la narrativa antes sugerida es totalmente forzada, pues existen otros varios casos en los que las Cortes no han acogido este tipo de demandas. Con todo, esta objeción puede ser rebatida, desde el momento que las causas que nuestra doctrina señala como las más significativas, son justamente a las que yo he hecho alusión. Es más, una de las causas que contradiría esta argumentación es justamente Garcia Sabugal con Fisco, que más adelante se comenta. Con todo, la presunta contradicción es solamente aparente, desde el momento que a diferencia de las ya citadas causas, en esa la vía de acción ha sido un recurso de protección, el que por su naturaleza expedita y urgente (o cautelar en palabras de la Corte) no permite el análisis de fondo y cuantitativo en cuanto a los daños, que es precisamente el que sí se puede realizar en un contexto de un juicio ordinario. Debo este argumento a Javier Barrientos.

16 CS, 7 de agosto de 1984. Considerando 9. A mayor abundamiento, puede verse también lo sentencia de la Corte de Apelaciones recaída en el caso Lolco, "Que, finalmente a este respecto, toda vez que el caso de autos claramente no dice relación con los ilícitos a que se refiere el artículo 44 de la Ley $\mathrm{N}^{\circ} 18.575$, con aquellos comprendidos en los artículos 6 y 7 del mismo texto fundamental, ni con los fundamentos que se reconocen para la responsabilidad objetiva, en apoyo de los razonamientos normativos no puede menos que recurrirse al criterio jurídico político de interpretación constitucional que aconseja preferir siempre una conclusión que proteja al individuo frente al Estado, cual ciertamente es lo reclamado frente a la legítima limitación impuesta a la propiedad de la actora", Corte de Apelaciones de Santiago, Rol N 6828-1999. "Sociedad Agricola Lolco con Fisco de Cbile". Considerando 10. La cursiva es mía. 
Otra manifestación de este mismo fenómeno (cultural) se da en lo que concierne a la situación de aquellas personas familiares de quienes fueron hechas desaparecer de manera forzosa por la dictadura militar. El actor principal en lo que se refiere a las demandas de justicia fundamentales (en el contexto de nuestro país) que se plantean han sido y siguen siendo los tribunales de justicia ${ }^{17}$, los que a través de interpretaciones que casuísticamente permiten derribar el inexpugnable muro que constituye la ley de amnistía, han sido los únicos que (ocasionalmente) dan algún tipo de respuestas a este tipo de demandas. A estas alturas, a 30 años de su dictación parece más que razonable preguntarse ¿por qué no, en vez de recurrir a interpretaciones judiciales que permiten la inaplicación casuística de la ley de amnistía, derechamente derogarla? Tratando de dar una respuesta a esto se puede encontrar explicaciones en la inercia parlamentaria en este $a^{a}$ bito $^{18}$, la cual por sí sola no es suficiente, pues se debe ahondar en las causas de esta inercia. Una importante y coincidente con la idea que se viene desarrollando, es que la ciudadanía ha preferido traspasarle estos temas a la judicatura. En otras (deportivas) palabras, lo que quiero señalar es que un ciudadano cuyas demandas de justicia en este ámbito no han sido satisfechas, va a correr primero a tribunales, antes que a solicitar respuestas de sus representantes o movilizarse para poner el asunto en perspectiva de las demás autoridades.

Por si hasta ahora no ha quedado totalmente claro lo que pretendo esbozar, es más o menos lo siguiente. Forma parte de nuestra narrativa como sociedad, la percepción de que quienes están encargados de hacer frente a cualquier tipo de demanda de justicia son nuestros tribunales. En otras palabras, parece ser algo que nos define que nuestra reacción automática frente a situaciones que percibimos como materialmente injustas sea, en vez de deliberar acerca de ellas, nutriéndonos con los puntos de vista de todos los sectores de nuestra comunidad, acudir a los tribunales. Hablando desde una cultura cuya teoría constitucional parte de la premisa de la soberanía del Parlamento, Jeremy Waldron señala, "el derecho aspira a la justicia, pero representa la aspiración de justicia de una comunidad, la cual-como Aristóteles enfatiza - no está compuesta por personas que piensan de manera similar, sino que de manera distinta, frente asuntos de común interés"19.

17 Se podrá rebatir esta línea de argumentación mostrando como ejemplos la labor de las Comisiones Rettig y Valech. Con todo y sin querer desestimar la contribución material y humana que han hecho estas, existe un área demasiado importante para los familiares y víctimas de violencia del Estado en la cual aquellas no han obrado el castigo para quienes a nombre del Estado ejecutaron tan horrorosos actos.

18 Otros buenos ejemplos de esta misma situación pueden encontrarse en la tramitación del proyecto de ley que crea el Instituto de Derechos Humanos y en los ya numerosos proyectos que han buscado crear la figura del Defensor del Pueblo o del Ciudadano.

19 Waldron, Jeremy (1999) Law and Disagreement. Oxford (Inglaterra): Oxford University Press, p. 6. La traducción es mía y la cursiva es del autor. 
Aunque la referencia es a alguien quien habla desde una cultura bastante distinta a la nuestra, nos hace reflexionar acerca de qué hemos de esperar de nuestros jueces (y en tanto representantes, de nuestros legisladores). Ya he explorado con anterioridad lo que cabría esperar de nuestros tribunales enfrentados a casos que plantean pretensiones de justicia material $^{20}$; por ahora, baste para los presentes propósitos con reconocer que dicha concepción no es la que forma parte de nuestra narrativa, tanto en 1890 como en la actualidad cuando un chileno ve de alguna manera afectada su propiedad por normas totalmente válidas, siente que son los tribunales quienes deben remediar esta situación de agravio y estos, por su parte, comparten esta percepción, no obstante la falta de un referente normativo, positivado por una decisión legislativa, que de manera expresa e indubitada establezca esta solución para casos como los que vengo señalando.

En consecuencia con lo antes señalado surge en el seno de nuestra cultura la tendencia a judicializar la política. Qué mayor evidencia de esta, que lo sucedido como consecuencia del primer gran movimiento social luego de la vuelta de la democracia, la revuelta pingüina. Dentro de las primeras propuestas que fueron lanzadas por la presidenta Bachellet, además de la creación de una comisión especial de naturaleza no parlamentaria, estuvo la de ampliar la esfera de aplicación del recurso de protección al tema del derecho a la educación ${ }^{21}$. La idea, en ese entonces, parecía ser más o menos así: Ante la dificultad que reviste poder deliberar en el Congreso sobre este tema, lo mejor es que sean los especialistas y los tribunales de justicia los que vayan ofreciendo soluciones frente a este tipo de demandas. ¿Por qué enfrascarse en una ardua lucha por lograr los consensos necesarios como para lograr el quórum requerido para aprobar una modificación a la Ley Orgánica de Educación, cuando los tribunales de justicia

Guiloff, Matías (s/d) "Injusticia (material) y Constitucionalidad". Paper presentado ante el Tercer Congreso de Derecho Constitucional de la Universidad de Chile, copia en poder del autor. Disponible en www.congreso.uchile.cl/htlm/pdf/ponencias/guiloff.pdf -

Ver El Mercurio 1 de junio de 2006, "Presidenta Bachelet anunció pase escolar las 24 horas y becas para PSU". Disponible online en http://www.emol.com/noticias/nacional/detalle/detallenoticias.asp? idnoticia $=220914$ [Fecha de visita 19 de diciembre de 2007]. Para una ilustrativa discusión al respecto véase la que tuvo ha lugar entre el profesor Domingo Lovera y los profesores Arturo Fermandois y Rodrigo Delaveau. Disponible online en http://editorial. elmercurio.com/archives/2006/06/debate_constitu.asp

Asimismo, véase también El Mercurio 20 de Diciembre de 2007, "UDI conforma equipo de abogados para llevar adelante acciones de carácter penal y civil". Disponible online en http:// diario.elmercurio.com/2007/12/20/nacional/politica/noticias/EA9CF6EF-DDF7-4D00830E-BD0AF6F4F936.hrm [Fecha de visita 21 de Diciembre de 2007]. 
(como siempre lo han hecho) pueden aliviar a quienes se sientan agraviados mediante sus sentencias? ${ }^{22 ; 23}$.

\section{La explicación institucional}

Más allá de estas muestras y de mi apreciación de que presentar estas demandas ante los tribunales de justicia forma parte de nuestra narrativa, me gustaría sugerir adicionalmente que la judicialización de la política forma parte de nuestra institucionalidad. Esto que de buenas a primeras puede sonar tan descabellado, es fácil de observar con la sola lectura del artículo 93 de nuestra Constitución, que establece las facultades del Tribunal Constitucional ${ }^{24}$. Proporcionarle este incentivo (que para efectos democráticos deliberativos no dudo en calificar de perverso) a nuestros legisladores les ha permitido poder abrir nuevas instancias dentro del proceso político y dejar que sean jueces quienes decidan profundos conflictos entre valores fundamentales que ellos eluden haciendo leyes demasiado vagas ${ }^{25}$. Con ello, como acabo de sugerir, se ha reducido notablemente la calidad del debate legislativo, en cuanto los integrantes de nuestro Congreso pueden vivir con la sensación de comodidad que les da el hecho que finalmen-

Una muestra más de lo mismo, aunque mucho más exagerada viene dada por el Recurso de Protección presentado en contra de la decisión de la Cámara de Diputados de rechazar el proyecto de ley que pretendía otorgar el derecho a aquellos chilenos que se encuentran en el extranjero de participar en las elecciones. El recurso se encuentra disponible online, http:// www.bachelet 2006.com/index.php?option $=$ com_content\&task $=$ view\&id $=1293 \&$ Itemid $=87$ \&lang =es [Fecha de visita 21 de diciembre de 2007]. Con todo, más que un caso de judicialización de la política, esto parece uno de lo que el profesor Fernando Atria ha denominado como el síndrome de la víctima insatisfecha. En general, Atria, Fernando (2000) "Revisión Judicial: el síndrome de la víctima insatisfecha”. Estudios Públicos, $\mathrm{N}^{\circ} 79,56 \mathrm{pp}$.

John Charney me criticó este argumento señalándome que justamente es por los altos quórums con que deben ser aprobados proyectos de ley que digan relación con materias reservadas a leyes de quórum calificado o leyes orgánicas constitucionales que muchas veces se debe ir en búsqueda de respuestas a órganos jurisdiccionales. Si bien no comparto plenamente el argumento, sí pienso que el fundamento que lo subyace, la reflexión acerca de los efectos para la deliberación de las leyes de quórum gravado en nuestra Constitución, debe ser objeto de mayor preocupación por nuestra teoría constitucional.

24 Véase específicamente las facultades contenidas en los numerales 1 [otorgándole al Tribunal Constitucional la facultad de ejercer (preventivamente) el control de constitucionalidad sobre Leyes de Reforma Constitucional, Leyes Orgánicas Constitucionales y Tratados Internacionales que versen sobre materias propias de estas últimas], 3 [atribuyéndole a este tribunal la facultad de conocer de cuestiones de constitucionalidad suscitadas en la tramitación de proyectos de ley, reformas constitucionales y tratados internacionales] y 16 de este artículo [otorgándole al Tribunal Constitucional la facultad de ejercer (de manera represiva, aunque como veremos abstractamente) el control de constitucionalidad sobre Decretos Supremos].

25 Para una acabada comprensión de este argumento, es necesario además de la lectura de la anterior referencia, la de los incisos finales del mismo artículo 93, los que para solicitar al tribunal el ejercicio de las atribuciones contenidas en los numerales 3 y 16 otorgan legitimidad activa al Presidente de la República, a cualquiera de sus cámaras o una cuarta parte de sus miembros y a cualquiera de las cámaras o una cuarta parte de sus miembros (tratándose de decretos que no excedan la potestad reglamentaria autónoma del Presidente), respectivamente. 
te no serán ellos quienes aparecerán ante la ciudadanía como directamente responsables de la priorización de un valor sobre otro en casos en los que existe un manifiesto conflicto entre ellos (requerimiento para un control de constitucionalidad preventivo) y qué mejor medio para esto que aprobar leyes bien vagas que les permitan posteriormente recurrir contra el decreto que necesariamente las debe complementar para dar algún tipo de regulación a la enormidad de situaciones que su (cómoda) labor legislativa ha dejado en la más absoluta de las incertidumbres (control constitucional represivo) ${ }^{26}$. Así nuestro texto positivo básico (quizás influida por esta suerte de narrativa que vengo esgrimiendo) institucionaliza la judicialización de la política. Aparte de las nefastas consecuencias para la deliberación democrática que esto acarrea, conlleva también desde el punto de vista de su aplicación en la práctica no pocas dificultades que enseguida paso a analizar.

\section{Algunas consecuencias de esta manera de resolver los des- acuerdos}

En primer lugar como ha señalado Mark Tushnet, el entrometimiento de los jueces en cuestiones políticas provoca distorsiones en la política pública $^{27}$, cuestiones de política pública que comisiones parlamentarias han establecido luego de numerosas y tediosas audiencias son borradas de un plumazo por jueces que en la soledad y aislamiento de su despacho tienden a ver solo el componente valórico y esto, cuando los temas vuelven al Parlamento, influye en la discusión legislativa de forma tal que al

Dentro de la práctica constitucional de Estados Unidos ha existido un enfoque diverso en relación al establecimiento de delegaciones demasiado vagas a favor del administrador. Esta doctrina judicial se denomina "Non- delegation" o "no delegación" y su punto focal es que el Congreso no puede hacer delegaciones de autoridad a la administración en las cuales no sea posible advertir, al menos, un principio inteligible mediante el cual el administrador guiado por una elección parlamentaria pueda limitar su discreción. Nótese como a diferencia de nuestro enfoque, que apunta más a proteger de manera estructural los derechos fundamentales estableciendo límites del contenido y alcance de la regulación que finalmente de ellos haga el administrador, la doctrina de non- delegation lo hace a que el Congreso haga su trabajo, legisle, estableciendo al menos en sus delegaciones una elección de un principio que permita limitar la discrecionalidad del administrador. Para una mirada más detallada a esta doctrina véase los fallos Panama Refining Co. v. Ryan, 293 U.S. 388 (1935) y A.L.A. Schechter Poultry Corp. v. United States, 295 U.S. 495 (1935). Con todo, siguiendo a John Hart Ely, esta doctrina murió por asociación, por cuanto al oponerse a programas que la administración de F. D. Roosevelt quería desarrollar para hacerle frente a la gran depresión, fue vinculada a muchas otras decisiones que declararon inconstitucional leyes sociales que eran vistas por la Corte como atentados contra la libertad de contrato, todas las cuales pueden ser subsumidas simbólicamente en el fallo Lochner v. New York, 198 U.S. 45 (1905), que hizo conocido a este tribunal como la "Corte Lochner". ElY, John (1980) Democracy and Distrust. Cambridge (Massachusetts): Harvard University Press, p. 133.

27 Tushnet, Mark (1999). Taking the Constitution away from the Courts. Princeton (New Jersey): Princeton University Press, pp. 57- 63. 
igual que en la versión posneriana del pragmatismo ${ }^{28}$, las argumentaciones de política pública son finalmente definidas por lo que señalan los jueces. Una segunda cuestión guarda estrecha relación con la idea de imponer límites a la deliberación política o, en otras palabras, de aquella labor que se le asigna usualmente a los jueces en una democracia constitucional de establecer las leyes para hacer leyes ${ }^{29}$, que no son otra cosa que las restricciones que los derechos fundamentales le imponen a los productos finales de la discusión parlamentaria, las leyes. El establecimiento de estas "leyes" tiene como función que ciertos valores que en el contexto de una comunidad política determinada se consideran como fundamentales no se vean tocadas por la legislación. Así expresada las cosas esto parece no guardar ninguna dificultad, sin embargo, esta apreciación es errónea. En "Democracy and Distrust", uno de los más sofisticados intentos por justificar la práctica de revisión judicial de leyes dentro de una sociedad democrática, John Hart Ely le dedica un capítulo entera a esta labor cuyo nombre es descubriendo valores fundamentales ${ }^{30}$. ¿Dónde podemos encontrarlos?, Ely se pregunta, para luego concluir que ninguna de las posibles fuentes parece dar una respuesta acertada al problema, teniendo como figura central a la de Alexander Bickel (el que acuñó la expresión dificultad contra mayoritaria para referirse a aquella que enfrentaba una Corte al invalidar actos del Congreso), de acuerdo al cual, ninguna es la respuesta que una pregunta errada produce ${ }^{31}$.

\section{Nuestros tribunales Y NUESTROS Desacuerdos}

En esta sección pretendo mostrar como nuestra práctica jurisprudencial ha tratado demandas por reconocimiento y redistribución. Permítaseme hacer notar una breve cuestión antes de empezar. Asumiendo (de manera pragmática y resignada) que son nuestros tribunales los que en el contexto de nuestra cultura intentan solucionar los desacuerdos que nos dividen, no puede dejar de mencionarse la dificultad que entraña emprender una labor de esta naturaleza, en otras palabras, no puede desconocerse el carácter de difícil de todos estos casos que buscan zanjar desacuerdos que nos dividen como comunidad, por lo que el llamado a adentrarse en el debate entre H.L.A. Hart y Ronald Dworkin parece tentador. Con todo,

\footnotetext{
28 Posner, Richard (1982) The Economics of Justice. Cambridge (Massachusetts): Harvard University Press, 432 pp.

29 Michelman, Frank (1999) Brennan and Democracy. Princeton (New Jersey): Princeton University Press, p. 6. La traducción es mía.

$30 \quad$ ELY (1980) 43 et seq.

31 Bickel, Alexander (1986) The least dangerous branch. $2^{\text {a }}$ ed. New Haven (Connecticut): Yale University Press, p. 103. La traducción es mía.
} 
no es mi intención en el presente artículo argumentar, al menos a tal nivel de abstracción, acerca de que es lo que los jueces deben hacer frente a estos $\operatorname{casos}^{32}$. Más bien, mi idea es discurrir normativamente en el terreno de la política judicial y particularmente en lo que dice relación con la fundamentación de las sentencias, acerca de las maneras en que la judicatura puede abordar estos asuntos, habida consideración del principio democrático establecido en el artículo $4^{\circ}$ de nuestra Constitución y partiendo desde la premisa que nos situamos en el contexto de una cultura que judicializa la política.

Dentro de estos lineamientos corresponde señalar que a la hora de diferenciar el rol de los tribunales de justicia en la aplicación del derecho, un autor como Klaus Gunther ${ }^{33}$ distingue entre discursos de fundamentación y de aplicación. Los primeros son propios de la actividad legislativa, mientras que son los últimos los que dicen relación con la actividad de los jueces, quienes están llamados a reconstruir los contenido jurídicos creados por el legislador para hacer posible su aplicación a casos concretos. Ya situados en el contexto de esta clase de discursos, cabe indagar acerca de la posibilidad de representar los intereses generales dentro de este contexto discursivo. Para Robert Alexy esto es posible y dentro de las Cortes Constitucionales tomaría una forma puramente argumentativa. Para que una representación de esta naturaleza pueda darse, nuestro autor señala como necesario el cumplimiento de dos condiciones: "1) la existencia de argumentos correctos y razonables, y 2) la existencia de personas raciona-

32 Cumplo con al respecto señalar que H.L.A. Hart en "The Concept of law" y siguiendo lo que antes ya había esbozado el juez Cardozo nos señala que en este tipo de casos el ordenamiento jurídico no contempla una solución, por lo que enfrentado a estos el juez hace uso de su discreción.

Es decir, ante la inexcusable tarea de resolver la cuestión que las partes han sometido a su consideración el juez crea el derecho sin ningún otro tipo de limitación que las presentes en su propia discreción. HART, H.L.A. (1994) The Concept of Law, $2^{\mathrm{a}}$ ed. New York (Estados Unidos): Oxford University Press, pp. 129 y 252, y CARDozo, Benjamin (1921) The nature of the judicial process. New Haven (Connecticut): Yale University Press, p. 103. Con todo, tanto para Hart como Cardozo, esta situación solo se presenta en casos extremos, por lo que es una problemática que no resulta tan agobiante para la filosofía del Derecho. HART (1994) 103 y CARDOZO (1921) 135.

Una diversa postura es la que Ronald Dworkin sostiene, postura que establece que para este tipo de casos sí existen estándares jurídicos dentro de una comunidad que permiten su resolución y estos son los principios. De esto se sigue que enfrentado a un caso difícil y habida consideración de la existencia de principios dentro de un ordenamiento jurídico, lo que hacen los jueces no es crear el derecho sino descubrir los principios que mejor calzan y son coherentes con las leyes y prácticas legales existentes y que establecen la mejor justificación moral para estas, mostrando de esta manera a la ley bajo su mejor perspectiva. DworKIN (1986) 90.

33 Günther, Klaus (1995) "Un concepto normativo de coherencia para una teoría de la argumentación jurídica". Doxa N $\mathrm{N}^{\circ}$ 17-18, pp. 271- 302. Citado por Lopera, Gloria "La problemática legitimidad de la justicia constitucional". Disponible online en http://www.cepc.es/rap/ Publicaciones/Revistas/8/AIB_005_227.pdf 
les que estén dispuestas y sean capaces de aceptar argumentos correctos y razonables, por la mera razón de que son correctos y razonables. Siguiendo en este orden de cosas y como ha notado Frank Michelman ${ }^{34}$, ya el hecho que el juez ponga sobre la balanza las particulares circunstancias de cada una de las partes, independientemente de cómo finalmente se resuelva el caso, es muestra que nuestro juez al menos está dispuesto a dialogar con la parte que ha planteado esta argumentación. Dicho de otra manera, la circunstancia que el juez pondere este interés frente a los demás que entran en juego permite a la parte que los esboza quedar con la sensación que sus argumentos han sido (materialemte) oídos. Sin embargo, y para los efectos de los limitados objetivos de la sección que aquí se están elaborando, lo que importa dejar en claro es que los jueces al resolver casos difíciles (independientemente de sí en definitiva resuelven sobre la base de principios o la de su sola discreción) para (al menos) oír cabalmente y poder entablar algún diálogo con las partes, deben poner sobre la balanza y ponderar los argumentos de unos y de otros.

\section{Adjudicación de demandas por reconocimiento}

Explicitada esta prevención, empecemos pues a analizar nuestra práctica jurisprudencial en casos en los que, en alguna medida, se plantean demandas por reconocimiento. El primero de estos es Corporación Metodista. El tribunal que aquí se pronuncia es la Corte Suprema en el contexto de un Recurso de Inaplicabilidad por Inconstitucionalidad. Las alegaciones del recurrente consisten en señalar que cualquier chileno que sea indígena puede llevar a cualquier otra persona a un juicio especial en el que el demandado no indígena se encuentra limitado en la defensa de sus derechos dada la disposición de la Ley 17.729 que hace prevalecer el título de merced sobre cualquier otro. Es decir, alega que esta ley al establecer este procedimiento especial para estos casos y hacer prevalecer el título de merced sobre cualquier otro discrimina arbitrariamente a todas aquellas personas que no son indígenas. Ante esta alegación la Corte señala que "ningún acto discriminatorio se efectúa al aplicar los referidos artículos, pues es evidente que la dictación de éstos tuvo como único propósito la protección de cierta categoría de personas para resguardar su debilidad social, cultural y económica frente a otros estamentos de la sociedad chilena que no se encuentran en las mismas condiciones, como lo son los indígenas del país" 35 . Como se puede observar, aquí la Corte pone fuertemente sobre la balanza la situación de desigualdad en que se encuentran los indígenas en 
nuestro país, lo que la hace concluir que una norma que les dé un trato preferencial, que obviamente va en perjuicio de otras personas, no implica una discriminación arbitraria en perjuicio de las últimas. Con todo, no obstante que la disposición de la Corte con cada una de las partes parece una dialógica, en lo que dice relación con las razones, más parece la de imponer sin dialogar, por cuanto la Corte solamente enuncia las cuestiones que la llevan a resolver el conflicto de la manera que lo hace, sin entrar a fundamentarlas. Dentro del contexto de una cultura (que judicializa la política) donde el tema de la igualdad, de la discriminación positiva (y consiguientemente el de la discriminación reversa) van a seguir siendo asiduos visitantes de nuestros tribunales de justicia, la Corte parece haber dejado en este caso pasar una valiosa oportunidad para referirse a las distintas concepciones de igualdad y a como estas entran a tallar en la adjudicación constitucional $^{36}$.

Distinta es la suerte que corren otros recurridos. Estoy hablando específicamente de una familia de Testigos de Jehová que en fiel cumplimiento a sus creencias, se niegan a someter a su hijo a transfusiones de sangre. Ante esta situación la Corte (solo) les dice "la negativa de los padres a reponer la sangre perdida pone en grave peligro su vida y es ilegal porque priva de la integridad física y de la vida a una persona, lo que se encuentra garantizado en el $\mathrm{N}^{\circ} 1$ del artículo 19 de la Constitución"37. Aquí, a las diferentes creencias y ritualidades propias de un grupo que integra nuestra comunidad política, la Corte no asigna ningún tipo de reconocimiento, cuestión que resulta preocupante porque si somos dworkinianos diríamos que entre los elementos que constriñen la discreción de los juzgadores se encuentra la misma garantía de la igualdad ante la ley y adicionalmente la de libertad de cultos. Con todo, la Corte ni siquiera tiene la deferencia de poner en la balanza estos intereses y explicarnos por qué la vida pesa más que la posibilidad de ser tratado por la ley de acuerdo a los distintivos rasgos que a uno como miembro de una determinada comunidad lo constituyen y también que la posibilidad de libremente ejercitar aquella religión que uno endosa, cuestiones que en el contexto de una sociedad secular como la nuestra no pueden ser tomadas como un artículo de fe, por lo que, al menos, si quiere dejárselas de lado se debe intentar argumentar por qué esto sería lo aconsejable para la adecuada disposición del asunto. Con todo, no quiero llamar a equívocos al tocar este caso, pues dada la situación que eran los padres y no la persona misma quien estaba tomando la decisión de rehusar el tratamiento, se justificaba una intervención como la que la Corte finalmente realizó. Sin embargo, para poder realmente dialogar con dicción nacional". Cuadernos de análisis juridico $\mathrm{N}^{\circ}$ 36. Escuela de Derecho, Universidad Diego Portales. 
la comunidad de Testigos de Jehová, la Corte debió haberles explicado que no obstante reconocerle su libertad de culto y su derecho a ser tratados por la ley de acuerdo a los particulares rasgos que los constituyen como comunidad, pesaba más, dadas las especiales circunstancias fácticas que configuraban este caso, el derecho del menor a no ver terminados sus días por una decisión que a esas alturas de su vida él no estaba capacitado para tomar con todo la autonomía que se requiere para tomar este tipo de decisiones.

Ningún reconocimiento tampoco recibieron los intereses de las mujeres que usando la píldora del día después pretendían decidir por sí mismas qué hacer con su sexualidad o al menos tener la posibilidad de decidir como un tema suyo si quería ingerir un medicamento que podía ser abortivo ${ }^{38}$. A diferencia de lo realizado en el tratamiento de los fallos anteriores, para este es imposible citar alguna parte de la sentencia en que la Corte exprese que está arbitrando dentro del contexto de un conflicto de intereses. La única oposición que plantea la Corte es la que se produce entre el derecho a la vida del feto y la resolución del Ministerio de Salud; sin embargo, no se hace mención alguna a qué tipo de intereses son los que podrían motivar a la adopción de una política pública como esta. Es tan palmario que la Corte no es capaz de identificar cualquier otro tipo de interés que no sea el del feto, que pese a que este es un fallo dividido, la controversia entre la mayoría y la minoría no es (al menos visiblemente) una que tenga que ver con cuestiones valóricas o, más bien dicho, con el peso que debiese ser asignado a cada valor en juego; si hay algo que se puede sacar en limpio del voto de minoría esto es tan solo en lo que se refiere a la naturaleza del recurso de protección y de los asuntos que en este pueden ser ventilados ${ }^{39 ; 40}$. Así, las mujeres que buscan autodeterminarse no reciben ningún tipo de feedback del tribunal, ni siquiera les dicen que es un valor importante que ellas puedan tomar por sí mismas relevantes decisiones para su vida sin que el Estado o su aparato coactivo se pueda inmiscuir en ello, pero que dado que entra en conflicto con el derecho a la

Corte Suprema, 30 de agosto de 2001. Rol No 2186- 2001. "Philippi Izquierdo, Sara, Nena, González, y otros con Laboratorio S.P.",

39 "Que, en armonia con lo consignado anteriormente cabe concluir que la presente vía no es la idónea para dilucidar el problema planteado por los recurrentes, siendo su resolución propia de un juicio declarativo, donde podrá establecerse en definitiva la naturaleza de la píldora y su modo de actuar en los embriones bumanos, todo lo que envuelve analizar informes científicos complejos y otras probanzas pertinentes $y$ decidir acerca de su verosimilitud", Corte Suprema. 30 de agosto de 2001. Rol N 2186- 2001. El destacado es mío.

40 Aunque, con todo, existe otra cuestión que resulta de interés cuando se evalúa desde alguna de las ideas que he venido planteando en este paper, pues la minoría señala que en un procedimiento de lato conocimiento podrían ser rendidas todas las probanzas pertinentes para probar cuestiones de orden científico como las planteadas por esta acción constitucional. Si hay algo que esto muestra es hasta qué punto se confía en judicializarlo todo, tanto que hasta se llega a creer que dentro de un proceso judicial se puede llegar a probar la naturaleza abortiva o no abortiva de la anticoncepción de emergencia. 
vida del feto, su interés debe ceder. Nada de eso, solo quedan con una inexpugnable y sorda argumentación de que nuestro ordenamiento jurídico protege de manera amplia los intereses del que está por nacer.

Una pequeña reflexión antes de adentrarme en el análisis de casos que dicen relación con redistribución. Como se puede observar, distinta es la actitud que tuvo el tribunal en los casos analizados. En Corporación Metodista parece sugerir que el ordenamiento jurídico puede ser sensible a desigualdades económicas, sociales y culturales y consiguientemente otorgar un trato diferenciado que incluso puede ir en perjuicio de los demás estamentos de la sociedad para grupos que se encuentren en esa situación de desigualdad. Una lectura que puede válidamente ser extraída de esto es que si bien las leyes y principios que nos gobiernan en principio deben ser generales, abstractas e idealmente permanecer inmutables a las peculiaridades que se puedan presentar, resulta aceptable que estos requerimientos cedan frente a situaciones que la realidad las indica como acreedoras de un trato diferenciado. Así, las leyes no se presentan como un inconmovible imperio que se encuentra ajeno a todo tipo de particularidades, por el contrario, pueden existir ocasiones en que la ley bajándose de su pedestal imperial y conectándose con la realidad establezca soluciones que estén atentas a las peculiaridades y situaciones de hecho de cada comunidad y a sus particulares contextos ${ }^{41}$. Como es fácil de constatar no fue esto lo que sucedió ni en el caso de la píldora como tampoco en el de los Testigos de Jehová. En estos casos la Corte visualizó a la Constitución como un lejano e inconmovible imperio, como un rígido código, que no podía sensibilizarse con los intereses y peculiaridades que por el otro lado entraban en juego ${ }^{42}$. Como antes señalé, el resultado del caso de los Testigos de Jehová bien pudo haber sido el mismo, pero la Corte al menos debió haber sido más receptiva a la posibilidad de autodeterminación de esta comunidad.

\section{Adjudicación de demandas por redistribución}

Esto es cuanto puedo señalar en lo que toca a nuestra práctica constitucional relativa a demandas de reconocimiento. En lo que sigue paso a analizar la que se ha generado en casos que dicen relación con cuestiones redistributivas ${ }^{43}$. El primero de ellos es el rol 246 del Tribunal

Michelman (1986) 14.

Véase en general Cover (1983), citado en Gargarella, Roberto. "El nacimiento del constitucionalismo popular: Sobre "The people themselves" de Larry Kramer". Disponible online en http:// www.juragentium.unifi.it/es/surveys/latina/gargarel.pdf [arguyendo que el rol de los jueces muchas veces es el de eliminar determinadas visiones sobre el derecho].

Como se podría observar a continuación, mi análisis de adjudicación de demandas de redistribución se refiere a casos en donde lo que está en cuestión son limitaciones al derecho de propiedad y la consiguiente obligación de indemnizar, si es que la limitación en verdad es una expropiación. Desde un punto de vista nominal se podría argüir que tales no constituyen 
Constitucional ${ }^{44}$. Con ocasión de un requerimiento presentado por un grupo de senadores y diputados en contra de un decreto del Ministerio de Bienes Nacionales regulando el acceso a las playas en caso de que no existan otras vías, para fines turísticos o de pesca. Dejando a un lado para los limitados propósitos de este paper el hecho que este decreto solamente venía a reglamentar un Decreto Ley de 1977 que establecía la obligación de facilitar de manera gratuita el acceso a estas playas ${ }^{45}$, lo que incidía de manera decisoria en las competencias que el Tribunal podría tener para revisar este requerimiento ${ }^{46}$, el caso resulta interesante en cuanto se configura por un conflicto entre bienes netamente privados (las propiedades que debían soportar la carga de ceder gratuitamente el acceso a la playa) y públicos (las playas adyacentes a esas propiedades, en su calidad de bienes nacionales de uso público). Con todo, el Tribunal parece no percibir este conflicto, pues se limita a señalar que "las playas son bienes nacionales de uso público y su uso pertenece a la Nación toda. En razón de la función social que debe cumplir el ejercicio del derecho de dominio la autoridad, en este caso el legislador, puede regular el acceso a dichos bienes, a través de los predios colindantes, para que no se desnaturalice el concepto de que son de la Nación toda. Lo que no puede hacer es privar del derecho de dominio y de sus atributos esenciales o hacer ilusorio el ejercicio del

claros casos de demandas por redistribución. Con todo, es mi parecer que sí podrían ser definidas como tales. En primer lugar, la clásica defensa de quienes deben soportar estas limitaciones es solicitar una indemnización. Indemnización que en su concepto es debida ya que el Estado les está quitando algo que les pertenece, con el objeto de poder beneficiar a la comunidad toda, por lo que, consecuentemente, esgrimen el derecho a la igualdad ante las cargas públicas. En segundo lugar, no puede desconocerse que la expropiación, sea que se la conciba como una garantía patrimonial sustantiva o como una garantía procesal, tiene un carácter antirredistributivo. En otras palabras, aquellas cláusulas en las constituciones que establecen el deber del Estado de compensar para el caso que afecte de manera grave la propiedad privada, si se me permite la expresión, están ahí para evitar que los gobiernos redistribuyan bienes a diestra y siniestra. En general, Sunstern, Cass (1994) The partial Constitution. Cambridge (Massachusetts). Harvard University Press, 428 pp.

44 Tribunal Constitucional, 2 de diciembre de 1996, Rol 245-246. Disponible online en http://www.tribunalconstitucional.cl/archivos/sentencias/Rol_245_246.doc [Fecha de visita 23 de diciembre de 2007 .

45 Aspecto que figuró como argumento principal de la respuesta del Ejecutivo y del informe que para la oportunidad emitió la Contraloría General de la República, por lo que válidamente el Tribunal podría haberlo esgrimido como argumento para fundar una resolución en lo dispositivo del fallo.

46 Recordemos que el requerimiento fue presentado en 1996, por lo que, habida consideración que el referente normativo en donde se encontraba establecida la limitación era un Decreto Ley de 1977 (la que fue reglamentada para su puesta en práctica por el Decreto Supremo 1 de 10 de enero de 1996), por lo que si es que se pretendía impugnar la limitación, que es precisamente lo que buscaban los requirentes, el problema se tornaba en uno de derogación sobrevenida o de inaplicabilidad por inconstitucionalidad, pero nunca en uno que permitiera su impugnación a través del control represivo de constitucionalidad de Decretos Supremos y Reglamentos, situación que originaba la falta de competencia del Tribunal Constitucional para pronunciarse como finalmente lo hizo. 
derecho por las limitaciones que impone" ${ }^{47}$. Como se puede observar, lo único que parece preocupar realmente al Tribunal no es la distribución de bienes que, en rigor, pertenecen a la Nación toda, sino que las limitaciones que se impongan para el fin de permitir el acceso a los bienes públicos no resulten tan gravosas para quien las soporta. Obviamente es esta una preocupación válida, pero no obstante ella al menos admite ser balanceada con la necesidad de que todos puedan acceder de manera gratuita a los bienes nacionales de uso público. En el contexto de un control concreto, en el sentido de que la regulación que dio origen a su interposición se encontraba vigente, pero a la vez abstracto, desde la perspectiva que ningún dueño de una propiedad que colindara con la playa había interpuesto algún tipo de reclamación, el Tribunal debió haber sido especialmente sensible a la naturaleza del bien que la regulación en cuestión tuvo por objeto. En otras palabras, ante la ausencia de certezas de cuán gravosa podía resultar esta carga en su aplicación en concreto, el Tribunal debió haber prestado mucha más atención a los importantes motivos que fundamentaron la regulación ${ }^{48}$. Con todo, finalmente optó por una postura bastante conservadora, en lo que a limitaciones a la propiedad se refiere y de esa manera se cegó frente a otros importantes valores que entraban en juego.

Distinta fue la situación en otro caso que dice relación con redistribución de bienes, y que, como podrá ser visto, también envuelve aspectos de reconocimiento, específicamente con el traspaso desde el dominio privado hacia la comunidad nacional en general y (desde otra perspectiva) a la comunidad pehuenche en particular, de la especie araucaria araucana. En el caso García Sabugal con Ministro de Agricultura ${ }^{49}$, ante un recurso de protección interpuesto por un agricultor que a raíz de la dictación de un decreto supremo se había visto privado de la posibilidad de talar esta especie, la Corte debió poner en la balanza el derecho de propiedad frente a la protección del medio ambiente. Esta vez la Corte sí puso efectivamente en la balanza ambos valores fundamentales para nuestro constituyente, al, por una parte, reconocer que "de los términos del citado Decreto Supremo $N^{\circ} 43$ se desprende una clara y evidente limitación al

TC, Rol 245-246, p. 31.

El Tribunal Constitucional parece no darse cuenta que una de las formas de regular es precisamente a través del establecimiento de limitaciones. De ahí, cuan onerosas estas puedan resultar, es una cuestión de un distinto orden. A lo que voy, la posibilidad de limitar parece ir de la mano con la de regular. De ahí que, en el contexto de ámbitos en los que es dable exigir un rol más activo del Estado hacia la consecución del bien común, tales como los que configuran la función social de la propiedad, el reproche a las limitaciones no puede ser per $s e$, sino tomando en cuenta las particularidades de los contextos donde esa limitación recaerá. Corte de Apelaciones de Santiago. 31 de mayo de 1990. Rol 158-90. "García Sabugal Mario con Ministro de Agricultura". Revista de Derecha y Jurisprudencia, tomo 87, $\mathrm{N}^{\circ} 2$, año 1990, segunda parte, sección quinta, pp. 122 y 129. 
derecho de propiedad de que son titulares los dueños de predios forestales, al imponérseles la prohibición de cortar, explotar y comercializar la especie vegetal denominada araucaria, dentro de los límites de los terrenos donde pudiere existir" ${ }^{50}$, pero por otra señalar "Que, entre aquellos derechos o valores superiores que el constituyente ha querido proteger, aún a costa de sacrificar determinados intereses de los individuos, se encuentran, entre otros, los relativos a la conservación del patrimonio ambiental, idea que surge del ya citado inciso $2^{\circ}$ del artículo $19 \mathrm{~N}^{\circ} 24$ del texto constitucional, y del $\mathrm{N}^{\circ} 8$ de ese mismo precepto, cuando señala que le establece restricciones específicas al ejercicio de determinados derechos o libertades para proteger el medio ambiente" ${ }^{51}$ y "que la extinción de esa especie cunífera, no solo pone en peligro la conservación del medio ambiente, sino que además constituye un atentado al patrimonio cultural de la nación que es también deber del Estado proteger e incrementar, habida cuenta que, siendo la Araucaria una de las especies forestales más antiguas del continente americano, ha significado desde sus más remotos orígenes, fuente de sustento, tradiciones y entorno natural de un subgrupo de mapuches, denominados pehuenches, quienes han hecho historia y soberanía a partir del pehuén, como así denominan a la Araucaria Araucana." 52 . En mi parecer es valioso lo que aquí hace la Corte, desde el momento en que no solo reconoce que el legítimo interés del propietario en explotar como le plazca su predio debe ceder al interés de la comunidad nacional en proteger el patrimonio ambiental, sino que también reconoce un uso distinto de la propiedad al mayoritariamente empleado por nuestra comunidad, específicamente como fuente de sustento tradiciones y entorno natural de la cultura pehuenche. Nótese como la Corte utiliza una aproximación de redistribución con reconocimiento, en el sentido que justifica la limitación a la propiedad en razón de las características propias de la cultura pehuenche ${ }^{53}$. En este caso la Corte demuestra que es posible abrirse a los distintos tipos de demandas que en una comunidad pueden surgir y además hace lo propio con un enfoque hacia el ejercicio de la jurisdicción en que lo relevante no es la realización de declaraciones categóricas y ciegas a cualquier tipo de particularidades que por la comunidad puedan ser esbozadas, sino que es oír a todas las partes, dejar que los hechos del caso le hablen y en ese contexto particular demarcado por los hechos poner las cosas en la balanza 
y determinar cuál de todos los valores en este específico contexto pesa más $54 ; 55$.

Así las cosas, entre las observaciones que se pueden extraer de la práctica constitucional chilena en relación a casos en los que se presentan aspectos de reconocimiento y redistribución se pueden destacar que cuando los jueces resuelven casos en los que van envueltos pretensiones de reconocimiento y redistribución, no lo hacen de acuerdo a categorías que solo pueden ser de alguna manera vinculada a los valores fundamentales establecidos por nuestra Constitución si la caracterización de los mismos procede a un alto nivel de generalidad. Muy por el contrario, la caracterización que se hace siempre es realizada en un nivel muy específico y guiada por los valores establecidos por nuestra Constitución. En este sentido, parece tomar fuerza la concepción del derecho como una práctica interpretativa más o menos constreñida ${ }^{56}$. Con todo, sí se observa discrecionalidad en esta misma etapa, cuando se deja de lado al caracterizar los casos otros valores que también aparecen específicamente establecidos por nuestra Constitución, como la igualdad ante la ley, la libertad de cultos, la privacidad y la idea de un derecho de propiedad limitado por su función social. También se puede observar discrecionalidad, a la hora de determinar el peso específico que los valores fundamentales han de tener a la hora de resolver una colisión entre estos. No obstante lo anterior, la específica mención de criterios sistémicos para interpretar la Constitución, como el

Con todo, debe señalarse que no es esta la postura más significativa para la doctrina en relación al tema de las limitaciones al derecho de propiedad. Esta puede ser extraída de los casos Galletué y Lolco, en todos los cuales la Corte accede a indemnizar al propietario que ha debido soportar una carga demasiado pesada, configurada por una limitación a su derecho de propiedad.

Al respecto véase en general, Al.Exy, Robert (2001) Teoría de los Derechos Fundamentales. Madrid. Centro de Estudios Políticos y Constitucionales, Madrid. En nuestro país véase ConTESSE, Jorge (2002). "Reglas y principios en Chile: Jerarquía entre derechos constitucionales?". Anuario de Filosofia Juridica y Social. Sociedad Chilena de Filosofía Juridica y Social. N ${ }^{\circ} 20$, pp. 58 y 59, arguyendo que "la importancia o peso de cada principio... no tiene un carácter objetivo y cerrado... la diferencia de importancia del principio está condicionada por las circunstancias que exigen su aplicación..." Todo esto se relaciona para Alexy con la tesis de la precedencia condicionada, según la cual "el mayor peso que un principio tiene en un caso está directamente condicionado por las circunstancias que reclaman su intervención, de manera tal que es perfectamente posible que en un caso un principio preceda, en su aplicación, a otro; y que, dadas unas otra condiciones, sea este último el que se aplique, precediendo al primero".

Asimismo, junto con ponderar lo que constituyen circunstancias fácticas, debe hacerse lo mismo con aquellas jurídicas, las que, en lo que dicen relación con este caso, presentan como singularidad de notable influencia para lo que finalmente se resuelva, el que se haya recurrido de protección, en vez de accionar por la vía de un juicio de responsabilidad extracontractual del Estado. Mientras que en el primer supuesto si la Corte acoge la pretensión del actor deberá declarar (de manera general) la inconstitucionalidad del decreto, en el segundo el decreto seguirá siendo constitucional, aunque el actor deberá ser indemnizado. 
esbozado por el Tribunal Constitucional en el fallo de playas públicas ${ }^{57}$ (entre varios otros casos) explicitan una disposición a realizar labores interpretativas de alguna manera constreñidas por el texto mismo de la Constitución.

\section{CONCLUSIONES}

A la hora de concluir este paper quisiera hacer una pequeña recapitulación de cuál ha sido la idea que he tenido en mente al escribirlo. En primer lugar he quierido postular que, nos guste o no nos guste, nuestra cultura jurídica es una que tiende a judicializar la política. Para esos efectos he mostrado como el mismo diseño constitucional favorece de manera bien explícita esta alternativa al establecer controles preventivos de constitucionalidad y represivos de regulaciones que buscan poner en práctica aspectos que nuestros parlamentarios han dejado (irresponsablemente) abiertos. Como corolario ha todo lo anterior he señalado que en el estado actual de las cosas no nos queda otra alternativa que aceptar que sean los tribunales los que terminen decidiendo sobre complejísimas demandas respecto a las cuales dentro de nuestro comunidad reina el desacuerdo.

Dada esta especial manera de resolver el desacuerdo, la labor de teorizar sobre la adjudicación en el contexto de nuestra filosofía del derecho parece una cuestión urgente. No obstante, no quiero ser malinterpretado, lo que estoy diciendo no es que como así son las cosas tenemos que contentarnos con filosofar dentro del statu quo y resignar la argumentación normativa en torno a otras maneras de enfocar la solución de los desacuerdos (que parecen mucho más correspondientes con una rigurosa lectura de la filosofía política) en nuestra comunidad. Es más, pienso que si lo que queremos es hacer reflexión normativa el statu quo jamás debe significar una vara imposible de $\operatorname{traspasar}^{58}$. Lo que sí he querido decir, es que dada la tendencia a judicializar nuestros desacuerdos ( $\mathrm{y}$ los fuertes incentivos constitucionales que para ese propósito existen), pragmáticamente parece urgente contar con un debate de buena calidad en lo que dice relación con la teoría de la adjudicación ${ }^{59}$.

Tribunal Constitucional, Rol 246, p. 33, "La Constitución es un todo orgánico y el sentido de sus normas debe ser determinado de manera tal que exista entre ellas la debida correspondencia y armonía" [Citando Rol 33 del mismo Tribunal].

Además, siguiendo a Cass Sunstein, no se puede evitar señalar que el statu quo no es neutral. Dicho de otra forma, está ahí por algo, es producto de una intervención de la sociedad, como cualquiera de las otras que a posteriori y cuando intentan ser llevadas a cabo, son atacadas por vulnerar este statu quo. Ver en general, Sunstein, Cass (1994) 68 et seq. 
Tratando de emprender esta (urgente) labor, he utilizado casos que dicen relación con dos de las demandas más fundamentales en nuestras sociedades, las de reconocimiento y redistribución. Al analizar nuestra práctica jurisprudencial he procedido sobre el entendido de descreer de los esencialismos o de absolutismos valóricos, esto me ha llevado a realzar la importancia de resolver (jurisdiccionalmente) estos conflictos poniendo en la balanza los intereses de cada parte, manera de proceder en la que independiente del resultado que finalmente se alcance, por lo menos deja a la comunidad con la idea de que todos los intereses son relevantes y que su menor preponderancia en la disposición de un caso en concreto, se explica por los específicos hechos que configuran el caso, los que en ciertas circunstancias (como claramente lo demuestra el caso de los Testigos de Jehová) hacen necesario que se le otorgue más peso a uno de los valores en juego que a otros. Finalmente, me he reservado algunos (escuetos) comentarios para tratar de evaluar esta manera de proceder a la luz del debate en la teoría general del derecho sobre adjudicación y he señalado que no obstante aparecer claramente que el texto constitucional tiende a guiar (eliminando la discrecionalidad) el proceso de interpretación constitucional, es también notorio que en lo que se refiere a la caracterización de valores que entran en juego en el caso y en el peso que finalmente se les da a ellos en su resolución, existen altos niveles de discrecionalidad que el texto constitucional, para su aplicación práctica, no constriñe.

Termino señalando lo relevante que resulta la reflexión filosófica en torno a la adjudicación. No obstante las fuertes inclinaciones que podemos sentir hacia aplicar nuestro propio sentido de lo que es justo e injusto, no debemos olvidar que para que estas decisiones puedan ser legítimas, estas deben cumplir con la orgánica que les establece un marco y además deben ser razonadas. El mismo Hart termina reconociendo en su post scríptum a "The Concept of law" que en la primera edición dejó de tocar un tema crucial: la adjudicación ${ }^{60}$. Sin perjuicio que desde el punto de vista de la filosofía política e incluso desde el punto de vista de los derechos sea bastante discutible darle un rol tan preponderante a la adjudicación, ante la evidencia de una práctica que tiende a judicializarlo todo (incluso determinaciones científicas como esboza el voto de minoría en píldora) debemos ser especialmente preocupados en no dejarla fuera de la filosofía del derecho. Dentro de este contexto, se hace especialmente necesario dejar de lado esencialismos y pasar a ponderar y razonar en torno a valores que entran en conflicto. En comunidades donde la Constitución le ha entregado la interpretación de los valores fundamentales contenidos en ella a orga-

podemos pretender llegar a un acuerdo en lo relativo a los valores fundamentales que fijarán el marco de todo lo que puede ser legislado, the laws of lawmaking. Michelman (1999) 48. La traducción es mía. 
nismos aislados de la política, urgente es exigirle que razonen y a la vez estar constantemente evaluando y criticando la calidad de sus argumentos, pues, como ha señalado Michelman ${ }^{61}$, dada la situación que se ha decidido dejar estos temas fuera de la deliberación política, el razonamiento que en torno a ellos se haga en tribunales es la única representación de razón práctica que en esos temas nos queda.

\section{Bibliografía CONSUlTADA}

- Alexy, Robert. (2001) Teoría de los Derechos Fundamentales. Madrid. Centro de Estudios Políticos y Constitucionales.

- (2006), "Ponderación, control de constitucionalidad y representación", en Andrés Ibáñez, Perfecto y Alexy, Robert, Jueces y ponderación argumentativa, México, UNAM, Instituto de Investigaciones Jurídicas.

- Atria, Fernando. (1997) "Los peligros de la Constitución. La idea de igualdad en la jurisdicción nacional". Cuadernos de análisis jurídico $\mathrm{N}^{\circ}$ 36. Escuela de Derecho Universidad Diego Portales.

- (2000) "Revisión Judicial: el síndrome de la víctima insatisfecha". Estudios Públicos, $\mathrm{N}^{\circ} 79$.

- Bickel, Alexander (1986) The least dangerous branch. $2^{\mathrm{a}}$ ed. New Haven (Connecticut): Yale University Press.

- Cardozo, Benjamin. (1921) The nature of the judicial process. New Haven (Connecticut): Yale University Press.

- Contesse, Jorge (2002). "Reglas y principios en Chile: ¿Jerarquía entre derechos constitucionales?". Anuario de Filosofía Jurídica y Social. Sociedad Chilena de Filosofía Jurídica y Social, N ${ }^{\circ} 20$.

(S/D) "Constitucionalismo interamericano: posibilidades no dogmáticas para el progreso". EN Gargarella, R., Rodríguez, C. \& Uprimny, R., Constitucionalismo Igualitario para América Latina (2008, en prensa).

- Couso, Javier (2004) "Consolidación democrática y Poder Judicial: los riesgos de la judicialización de la política". Revista de Ciencia Politica. $24 \mathrm{~N}^{\circ} 2$.

- Cover, Robert (1983) "Nomos and Narrative". Harvard Law Review. Vol. 97.

- Dworkin, Ronald (1987) Law's Empire. Cambridge (Massachusetts): Belknap Press.

- Ely, John (1980) Democracy and Distrust. Cambridge (Massachusetts): Harvard University Press. 
- Espejo, Nicolás (2007) "Reconocimiento y redistribución: el rol de una teoría crítica de la democracia". En Rodolfo Arango (editor académico): Filosofía de la democracia. Fundamentos conceptuales. Bogotá (Colombia): Siglo del Hombre Editores

- Günther, Klaus (1995) "Un concepto normativo de coherencia para una teoría de la argumentación jurídica". Doxa No 17-18, pp. 271-302.

- Hart, H.L.A. (1994) The Concept of Law. $2^{\mathrm{a}}$ ed., New York: Oxford University Press.

- Michelman, Frank (1986) "Traces of Self- Government", Harvard Law Review. Vol. 100.

- Michelman, Frank (1999) Brennan and Democracy. Princeton (New Jersey): Princeton University Press.

- Posner, Richard (1982) The Economics of Justice. Cambridge (Massachusetts): Harvard University Press.

- Rallo Lombarte, Artemi (2002) La Constitucionalidad de las Administraciones Independientes. Madrid: Editorial Tecnos.

- Sunstern, Cass (1994) The partial Constitution. Cambridge (Massachusetts): Harvard University Press.

- Tushnet, Mark. (1999) Taking the Constitution away from the Courts. Princeton (New Jersey): Princeton University Press.

- Waldron, Jeremy (1999) Law and Disagreement. Oxford (Inglaterra): Oxford University Press. 